\title{
Pronominal reference in sentences about persons or things: an electrophysiological approach
}

Citation for published version (APA):

Hammer, A., Jansma, B. M., Lamers, M. C., \& Munte, T. F. (2005). Pronominal reference in sentences about persons or things: an electrophysiological approach. Journal of Cognitive Neuroscience, 17(2), 227239. https://doi.org/10.1162/0898929053124947

Document status and date:

Published: 01/01/2005

DOI:

10.1162/0898929053124947

Document Version:

Publisher's PDF, also known as Version of record

Document license:

Taverne

Please check the document version of this publication:

- A submitted manuscript is the version of the article upon submission and before peer-review. There can be important differences between the submitted version and the official published version of record.

People interested in the research are advised to contact the author for the final version of the publication, or visit the DOI to the publisher's website.

- The final author version and the galley proof are versions of the publication after peer review.

- The final published version features the final layout of the paper including the volume, issue and page numbers.

Link to publication

\footnotetext{
General rights rights.

- You may freely distribute the URL identifying the publication in the public portal. please follow below link for the End User Agreement:

www.umlib.nl/taverne-license

Take down policy

If you believe that this document breaches copyright please contact us at:

repository@maastrichtuniversity.nl

providing details and we will investigate your claim.
}

Copyright and moral rights for the publications made accessible in the public portal are retained by the authors and/or other copyright owners and it is a condition of accessing publications that users recognise and abide by the legal requirements associated with these

- Users may download and print one copy of any publication from the public portal for the purpose of private study or research.

- You may not further distribute the material or use it for any profit-making activity or commercial gain

If the publication is distributed under the terms of Article $25 \mathrm{fa}$ of the Dutch Copyright Act, indicated by the "Taverne" license above, 


\title{
Pronominal Reference in Sentences about Persons or Things: An Electrophysiological Approach
}

\author{
Anke Hammer ${ }^{1}$, Bernadette M. Jansma ${ }^{1}$, \\ Monique Lamers ${ }^{2}$, and Thomas F. Münte ${ }^{3}$
}

\begin{abstract}
German pronouns ( $\mathrm{er}_{\mathrm{MALE} / \text { masculine, }}$ sie $\left.\mathrm{FEMALE}_{\mathrm{feminine}}\right)$ that refer to a person are determined by the biological gender (MALE/FEMALE) and/or syntactic gender (masculine/feminine) of the person. Pronouns ( $\left.\mathrm{er}_{\text {masculine }}, \mathrm{sie}_{\mathrm{feminine}}\right)$ that refer to a thing are determined by the syntactic gender of this thing (Garten [garden] masculine, Tasche [hand-bag] feminine). The study aimed to investigate whether semantic integration, syntactic integration, or both are involved in establishing co-reference between pronoun and subject/antecedent in sentences. Here we focused on two event-related potential components: the SPS/P600, related to syntactic violation and reanalysis, and the N400 component, related to semantic integration problems. In one condition, a person was introduced as antecedent and later referred to by a pronoun, which either agreed in biological/syntactic gender or not (biological/syntactic gender
\end{abstract}

\section{INTRODUCTION}

The phenomenon of establishing co-reference with one item in a sentence, for example, a pronoun, referring back to an element mentioned earlier in the sentence, is a central topic in attempts to understand language comprehension. The question about the underlying cognitive and neural mechanism of the co-reference, as well as the question what kind of information is accessed during comprehension of anaphoric expression, has attracted the interest of linguists, psycholinguists, and neuroscientists for quite some time and is still a matter of debate (Swaab, Camblin, \& Gordon, 2004; Schmitt, Lamers, \& Münte, 2002; Gordon \& Hendrick, 1998; Osterhout, Bersick, \& McLaughlin, 1997; Carreiras, Garnham, Oakhill, \& Cain, 1996; Hankamer \& Sag, 1976). In this study, we focus on pronominal reference as exemplified by the sentence "The woman is happy because she is in love." or, as in the German sentence, "Die Blume ist schön, weil sie viel Sonne hatte. (The flower is beautiful because it ('she') had a lot of sunlight.)" Reading these sentences, the compre-

\footnotetext{
${ }^{1}$ Maastricht University, The Netherlands, ${ }^{2}$ University of Nijmegen, The Netherlands, ${ }^{3}$ Otto-von-Guericke-Universität, Magdeburg, Germany
}

violation). In a second condition, a thing was introduced as antecedent and the corresponding pronoun either agreed in syntactic gender or not (syntactic gender violation). Results at critical pronouns showed a P600 effect for incongruent compared with congruent pronouns in both conditions with a centro-parietal maximum. This effect was larger for the person compared to the thing condition. We interpreted this finding as reflecting a syntactic integration process that can be influenced by conceptual/semantic and syntactic information of the antecedent type. Furthermore, at the word following the pronoun, we observed an N400 for the thing but not for the person condition. We suggest, supported by the results of a control experiment, that this effect reflects continuous integration processes for things, whereas for persons the integration seems to be finished at pronoun position.

hender knows that she refers back to the noun. But how does he or she know this? Some psycholinguistic studies have shown the involvement of conceptual/semantic information (Gernsbacher, 1991) to establish the link, others have suggested that it involves syntactic information, that is, more surface-related processing (Gordon \& Hendrick, 1998), or both (Garnham, Oakhill, Ehrlich, \& Carreiras, 1995).

Garrod and Sanford (1994) presented a model with two stages for pronoun interpretation (see also Garrod \& Terras, 2000) with (1) a bonding or immediate recovery stage, which is an automatic, more syntaxrelated process associated with establishing a link between anaphor and a previous expression, and (2) a resolution or immediate integration stage, which is testing and resolving this link. The integration is responsible for evaluating the established link (i.e., by weighting syntactic and semantic discourse information). In case of congruency, the integration process finishes with a so-called commitment. In case of incongruency, the integration process fails or is delayed.

We made use of event-related potentials (ERPs) to further investigate pronoun processing. ERPs are minute voltage fluctuations of electrical activity produced by neurons in the brain that are recorded from various 
points on the scalp during the processing of cognitive tasks (Rugg \& Coles, 1995; for language, Kutas, Federmeier, Coulson, King, \& Münte, 2000). Their high temporal resolution can be used to zoom into temporal aspects of establishing co-reference. Specific ERP components (i.e., the N400 and the P600) can be interpreted as showing semantic and/or syntactic processing.

Previous ERP studies on pronoun processing reported a variety of findings. For example, Osterhout and Mobley (1995) compared the ERPs to personal pronouns that either matched or mismatched the subject noun in biological gender as in "The aunt heard that she/he had won the lottery." They found that the mismatching pronouns elicited a P600 for participants judging such sentences as unacceptable. According to the authors, this P600 effect indicated syntactic integration. For participants who found such sentences acceptable, the ERPs to the mismatching trials included a larger negativity compared to matching trials, beginning at approximately $200 \mathrm{msec}$ after pronoun onset. This negativity was interpreted as a consequence of adding new elements to the existing representation in order to make sense of the mismatching pronoun sentence.

Osterhout, Bersick, et al. (1997) investigated reflexive pronouns that referred to (i) definitionally or (ii) stereotypically male or female antecedents. One example would be: (i) The man prepared himself/herself for the interview. (ii) The doctor prepared himself/herself for the operation. Overall, the results showed that ERPs to gender-incongruent pronouns were more positive than to congruent pronouns. Moreover, violations of gender definitions were more positive than violations of gender stereotypes. The authors concluded that ERPs are sensitive to violations of gender based on occupational stereotypes and that the observed ERP response is similar to the P600 elicited by syntactic anomalies (as shown by Hagoort, Brown, \& Groothusen, 1993; Osterhout \& Holcomb, 1992; for a review, see Hagoort, Brown, \& Osterhout, 1999). The P600 has also been observed in situations requiring the reanalysis of the sentence (Münte, Heinze, Matzke, Wieringa, \& Johannes, 1998; Friederici \& Mecklinger, 1996).

King and Kutas (1997) (see also Kutas, Federmeier, et al., 2000) examined the response to pronouns that refer to a stereotypically male or female antecedent noun. The subject noun in the experimental sentence was an occupational title that was more or less likely to be filled by a person of female or male gender (i.e., "The engineer redesigned the circuit because he/she had detected a flaw.') As one might expect, the paucity of female engineers in reality renders the version of this sentence with "she" odd at first glance. Readers appear to treat the female pronoun as mismatching. One of the major findings of this study was that mismatching pronouns elicited a larger N400 component compared to matching pronouns. This $\mathrm{N} 400$ has been shown to be sensitive to semantic integration (Kutas \& van Petten,
1994; Kutas \& Hillyard 1980, 1983), as well as to discourse integration (St. George, Kutas, Martinez, \& Sereno, 1999; van Berkum, Hagoort, \& Brown, 1999). The observed effect therefore indicates an involvement of semantic (world knowledge of stereotypes) and/or discourse processing of words during the integration of the pronoun into the sentence.

The results by Osterhout, Bersick, et al. (1997) or Osterhout and Mobley (1995) are, at first glance, contrary to the results presented by King and Kutas (1997). However, a direct comparison is difficult due to the difference in design and material. For example, a reflexive pronoun has to be bound in its governing category, whereas a nonreflexive pronoun has to be free. Furthermore, reflexive pronouns, once processed, can only be syntactically correct or incorrect in the given sentence context, whereas personal pronouns offer more degrees of freedom in the interpretation. For example, in case of a mismatch, the parser may leave the sentence level and search within the discourse level for an appropriate antecedent, indexed by the negativity reported by Osterhout and Mobley. In addition, the observed P600 difference in the Osterhout, Bersick, et al. study could alternatively be interpreted as an effect of semantic knowledge about gender stereotypes affecting the syntactic process. Then, semantic processing seems to be involved in the resolution process shown by the P600 variation between stereotype gender violations and clear biological gender violation conditions.

In a recent study, Schmitt et al. (2002) examined the separate effect of biological and syntactic gender violation during pronoun processing. The study was conducted in German because the German language differentiates between biological gender (FEMALE/MALE) and syntactic gender (feminine, masculine, neuter), especially in the cases of diminutives (das Bübchen MALE/ $_{\text {- }}$ neuter [the little boy]). Subjects read sentences in which

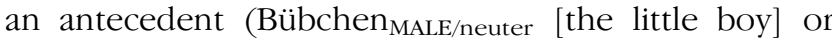

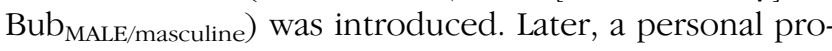
noun ( $\mathrm{er}_{\text {MALE/masculine/ }} / \mathrm{es}_{\text {neuter }} / \mathrm{sie}_{\text {FEMALE/feminine}}$ ) was presented which either agreed with the antecedent in terms of both gender types, in terms of syntactic gender only, or in terms of biological gender only, or violated both agreements. Overall, the results showed salient P600 effects for pronouns, with the violations being more positive than the nonviolations. This indicated that the establishment of reference involves syntactic reanalysis. Furthermore, the authors observed N400 effects in sentences with nondiminutives (violations being more negative than nonviolations), but not with diminutives. This showed that conceptual/semantic integration is involved during nondiminutive but not during diminutive pronoun processing; at least it could not be violated.

Taken together, the ERP pronoun studies so far did not reveal a clear pattern with regard to the question, what kind of information is used for linking a pronoun to its antecedent. The observation of N400 or P600 as 
indexes for semantic and syntactic processing, respectively, seems to be dependent on the type of pronoun and the type of antecedent. In addition, the interpretation of the P600 should be broadened. It can be a pure syntactic marker, but it can also be manipulated by semantic information (Münte, Heinze, et al., 1998). Also note that all these studies focused the ERP analysis on the pronoun position. It is therefore open so far, if and how the co-reference process proceeds after pronoun input, a point that will be addressed especially in the second experiment.

The aim of the current study is to further investigate the establishment of conceptual/semantic and syntactic gender agreement during pronoun processing. Specifically it was of interest, whether or not these processes differ for persons and things as antecedents. In contrast to English, German nouns referring to things have a very strong syntactic gender, which is independent of any semantic information. Garden, for example, is masculine ( der $_{\text {masculine }}$ Garten masculine$)$, and flower is feminine (die $_{\text {feminine }}$ Blume $\left._{\text {feminine }}\right)$, although neither of these things are male nor female. We assume to tap into unambiguous syntactic processing in this condition, reflected by a P600. Similar to English, a German noun referring to a person has a gender that is determined by the biological/conceptual gender. A woman, for example, has a female biological gender and a feminine

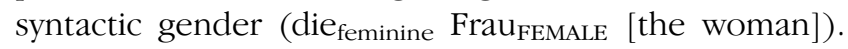
Because the two gender types coincide in this case, it is unclear which information is used by the linguistic system to establish co-reference between the pronoun "sie (she)" and the noun "die Frau." It could be semantic information, syntactic information, or both. Based on previous ERP findings, we consider three possible types of outcomes. If only biological gender (conceptual/semantic information) plays a role for persons, then we would expect an N400 ERP effect in violations of biological gender assignment (according to the results of King \& Kutas 1997). If biological and syntactic gender plays a role, we would expect an N400/ P600 complex for double violations (as was observed by Schmitt et al., 2002), reflecting a more modular and independent semantic and syntactic processing. ${ }^{1}$ Alternatively, one could expect a difference between the P600 amplitude in the person compared to the thing pronoun manipulation (as was observed in the stereotype vs. clear biological gender violations by Osterhout, Bersick, et al., 1997), indicating an interaction of semantic and syntactic processing within the $\mathrm{P} 600$ component.

German subjects read sentences in which an antecedent was either a person (P) or a thing $(\mathrm{T})$. This antecedent was introduced in the first phrase. In the second phrase, a pronoun was presented which referred back to the antecedent in the first phrase (congruent pronoun C) or which was incongruent (I) with the antecedent (examples are given in Table 1).

\section{EXPERIMENT 1}

\section{Results \\ Comprehension Task}

The correct performance in the comprehension task was $83 \%$, indicating that the subjects had indeed read and processed the sentences. Mean reaction time was 1800 msec (SD 350).

\section{Event-related Potentials}

The grand average ERPs, time-locked to the onset of the critical pronoun, are shown in Figure 1 for personantecedents, and in Figure 2 for thing-antecedents conditions.

The critical words elicit the N1-P2 complex that is typical for visually presented material, followed by a late negativity. In both antecedent conditions, incongruent compared to congruent pronouns are characterized by a more negative waveform in the range of 300-400 msec after pronoun onset, especially at parietal sites. From $400 \mathrm{msec}$ after onset and extending well into the ERP to the next word, the ERP to the incongruent stimuli is more positive than that to the congruent pronouns. This P600 effect is larger for sentences with a person compared to things as an antecedent.

\section{Negativity}

Results of the repeated-measures analyses of variance (ANOVAs) on mean amplitudes for the $300-400 \mathrm{msec}$ time window are reported in Table 2 . The omnibus ANOVA revealed a main effect of pronoun type with ERPs to incongruent conditions being more negative than congruent conditions. The interaction of antecedent type with pronoun type showed a trend. These

Table 1. Example Materials for the Experiment

\begin{tabular}{|c|c|}
\hline Condition & Sentence \\
\hline \multicolumn{2}{|c|}{ P: Person as antecedent } \\
\hline C. congruent & $\begin{array}{l}\text { Die } \text { Frau }_{\text {FEMALE }} \text { ist beliebt, } \\
\text { weil sie } \text { siemALE/feminine }_{\text {Fehön ist. }} \text { schen }\end{array}$ \\
\hline I. incongruent & $\begin{array}{l}\text { Die Frau } \\
\text { weil } \mathbf{e r}_{\text {MALE }} / \mathbf{m a s c u l i n e} \\
\text { schön ist. }\end{array}$ \\
\hline
\end{tabular}

\section{T: Thing as antecedent}

C. congruent

I. incongruent

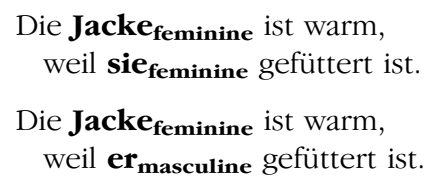

Translation: P: The woman is popular, because she/he is beautiful. T: The jacket is warm, because she/he is lined. FEMALE $=$ biological gender; masculine $=$ syntactic gender masculine; feminine $=$ syntactic gender feminine. 
Figure 1. Grand average ERPs time-locked to the onset of the critical pronoun in sentences with a person as the antecedent at a selected set of electrodes (negativity is up and each hash mark represents 200 msec of activity in this and in the following figures).

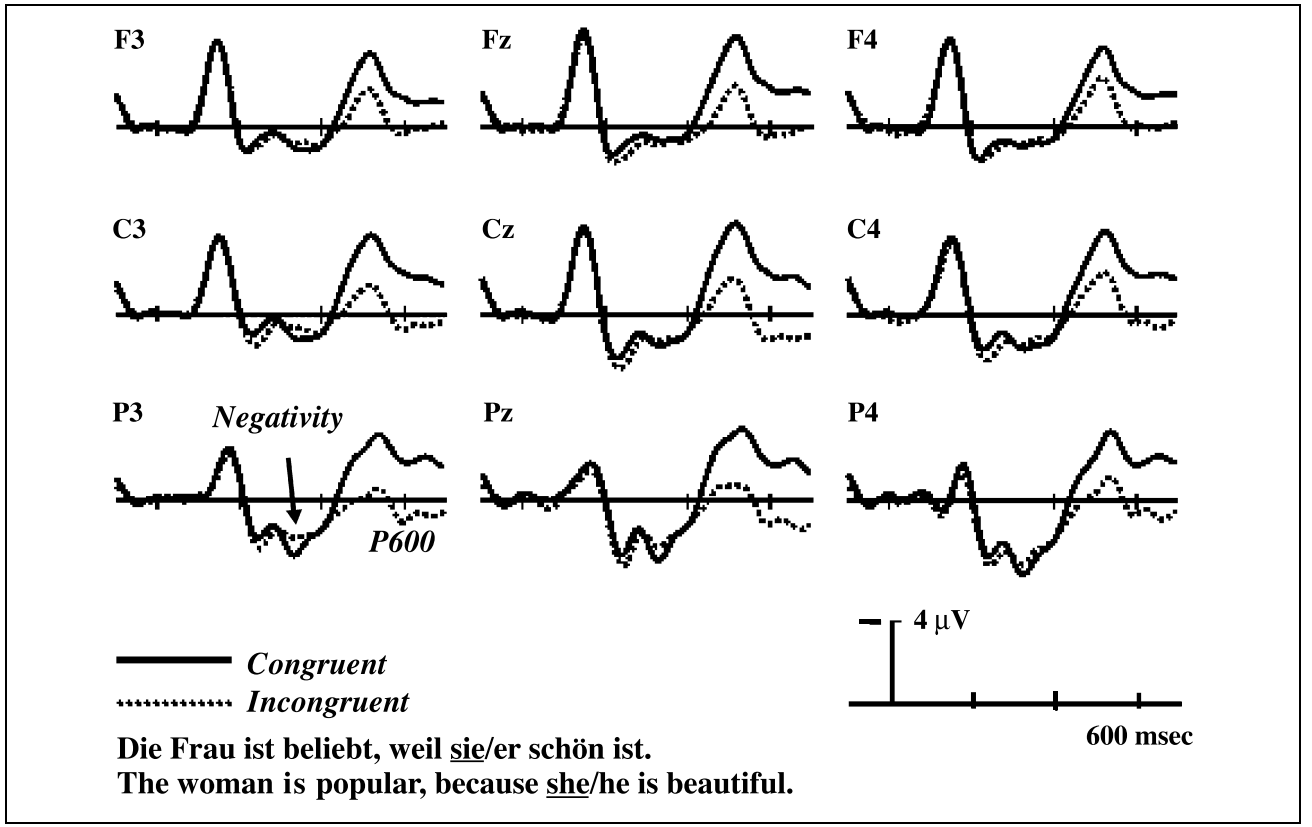

The woman is popular, because she/he is beautiful. effects were traced back to the following effects in separate ANOVAs for each antecedent type. For thingantecedents, the ANOVA including 29 electrodes showed a significant main effect of pronoun type. For personantecedents, the analysis including 29 electrode sites revealed a trend for Pronoun type $\times$ Electrode interaction. The pronoun type effects (negativity: incongruent minus congruent) are plotted in Figure 3 (left panel), separately for the two antecedent types.

\section{P600}

The omnibus ANOVA revealed no significant main effect for the antecedent types (see Table 3). There was a significant main effect of pronoun type with ERPs to incongruent pronouns being more positive than those to congruent ones. As visible in the ERP waves, and in Figure 3 (right panel): the pronoun-type effect (incongruent - congruent) for person-antecedent was much larger than for thing-antecedents. This difference was statistically reliable, as indicated by the significant interaction of Antecedent type $\times$ Pronoun type.

\section{End of Sentence Effects}

Figure 4 shows the grand average ERPs, time-locked to the onset of the critical pronoun up to the end of the sentence for things (left panel) and persons as anteced-
Figure 2. Grand average ERPs time-locked to the onset of the critical pronoun in sentences with a thing as the antecedent at a selected set of electrodes.

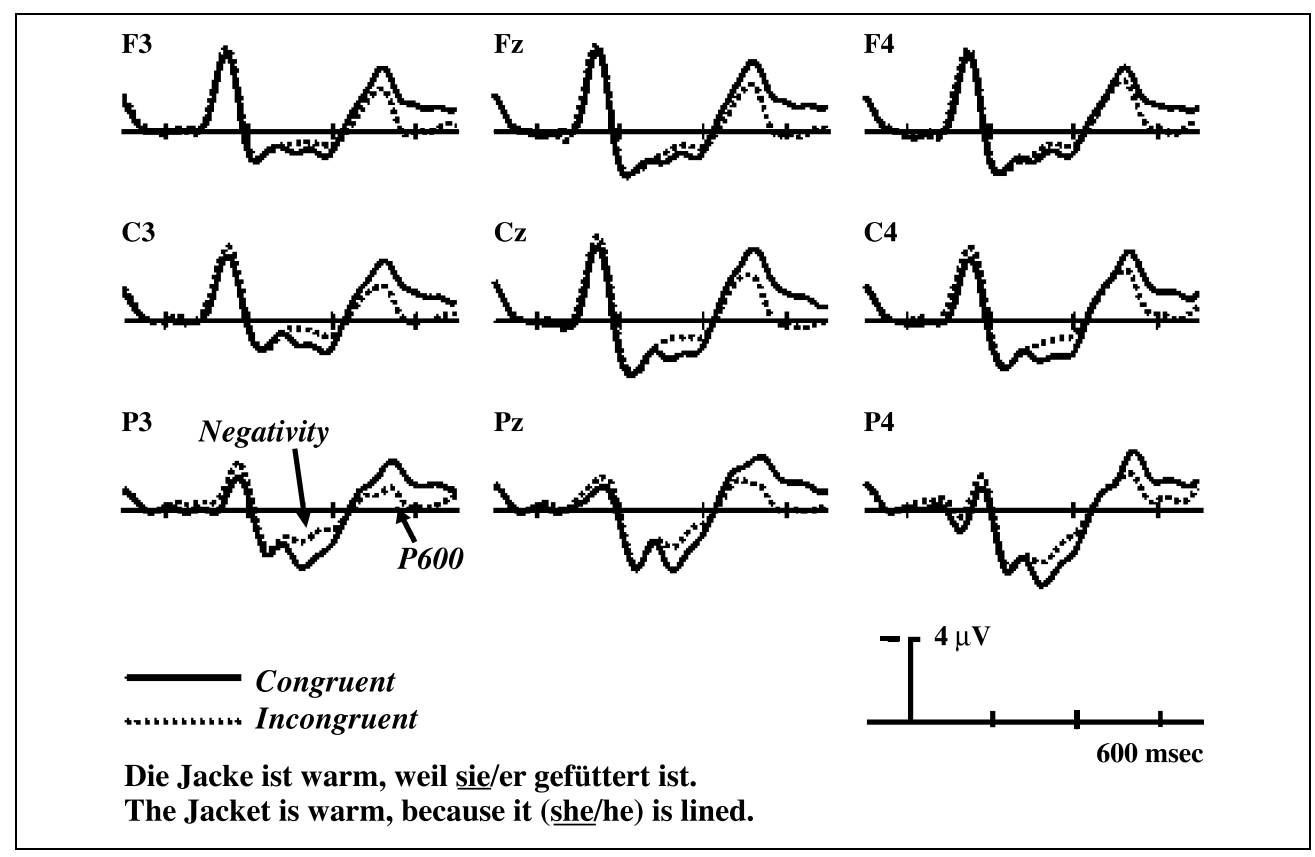


Table 2. Gender Agreement Effects: Mean ERP Amplitude ANOVAs in the 300-400 msec Latency Range (Negativity)

\begin{tabular}{lccc}
\hline Source & $d f$ & $F$ & $P(G G)$ \\
\hline Omnibus ANOVA (29 electrodes) & & & \\
Antecedent type (Person vs. Thing) & 1,15 & 0.08 & .8 \\
$\begin{array}{l}\text { Pronoun type (Congruent } \\
\quad \text { vs. Incongruent) }\end{array}$ & 1,15 & 4.59 & $.048^{*}$ \\
Antecedent type $\times$ Pronoun type & 1,15 & 3.81 & .07 \\
Antecedent type $\times$ Electrodes & 28,420 & 1.70 & .2 \\
Pronoun type $\times$ Electrodes & 28,420 & 1.92 & .1 \\
Antecedent type $\times$ & 28,420 & 1.02 & .4 \\
$\quad$ Pronoun type $\times$ Electrodes & & &
\end{tabular}

Person: Omnibus ANOVA (29 electrodes)

$\begin{array}{lccc}\text { Pronoun type (PC vs. PI) } & 1,15 & 0.92 & .35 \\ \text { Pronoun type } \times \text { Electrodes } & 28,240 & 2.26 & .08\end{array}$

Thing: Omnibus ANOVA (29 electrodes)

\begin{tabular}{lccc} 
Pronoun type (TC vs. TI) & 1,15 & 7.92 & $.01 *$ \\
Pronoun type $\times$ Electrodes & 28,240 & 1.08 & .37 \\
\hline
\end{tabular}

$\mathrm{PC}=$ congruent person; $\mathrm{PI}=$ incongruent person; $\mathrm{TC}=$ congruent thing; $\mathrm{TI}=$ incongruent thing; $\mathrm{GG}=$ Greenhouse-Geisser corrected $p$ value for $F$ tests with more than one degree of freedom.

$* p<.05$.

ents (right panel), respectively. In addition to the ERP pattern described before, Figure 4 (left panel) shows a more negative waveform for the word after the pronoun ("gefüttert") in incongruent sentences about things as compared to congruent sentences. This negativity begins at approximately $1000 \mathrm{msec}$ after the pronoun and lasts to $1300 \mathrm{msec}$ (corresponding to

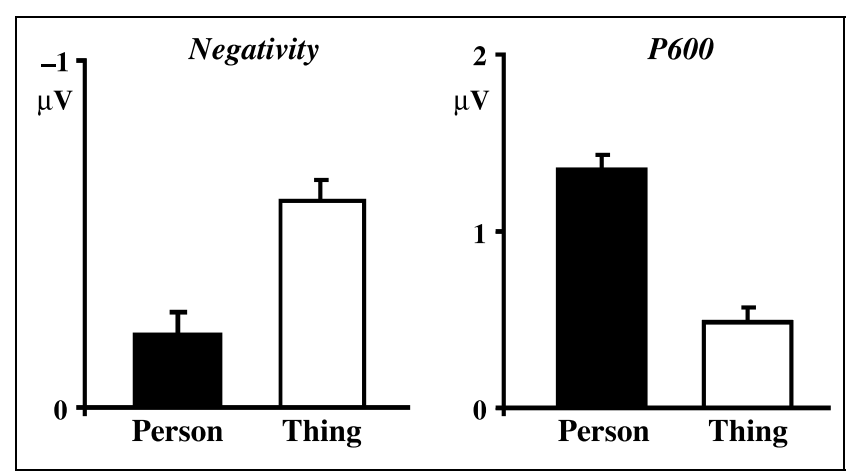

Figure 3. Mean amplitudes of the difference waves (incongruent minus congruent) are demonstrated for the negativity (time window $300-400 \mathrm{msec}$ ) at the left and the P600 (time window 400-700 msec) at the right.
Table 3. Gender Agreement Effects: Mean ERP Amplitude ANOVAs in the 400-700 msec Latency Range (P600)

\begin{tabular}{lrrl}
\hline Source & $d f$ & $F$ & $P(G G)$ \\
\hline $\begin{array}{l}\text { Omnibus ANOVA (29 electrodes) } \\
\text { Antecedent type (Person vs. Thing) }\end{array}$ & 1,15 & 0.12 & .7 \\
$\begin{array}{l}\text { Pronoun type (Congruent } \\
\quad \text { vs. Incongruent) }\end{array}$ & 1,15 & 15.16 & $.001^{* *}$ \\
Antecedent type $\times$ Pronoun type & 1,15 & 9.79 & $.007^{*}$ \\
Antecedent type $\times$ Electrodes & 28,420 & 1.28 & .3 \\
$\begin{array}{l}\text { Pronoun type } \times \text { Electrodes } \\
\text { Antecedent type } \times \text { Pronoun }\end{array}$ & 28,420 & 7.08 & $.0001^{* *}$ \\
$\quad$ type $\times$ Electrodes & 28,420 & 1.35 & .2 \\
\hline
\end{tabular}

$\mathrm{PC}=$ congruent person; $\mathrm{PI}=$ incongruent person; $\mathrm{TC}=$ congruent thing; TI = incongruent thing; GG = Greenhouse-Geisser corrected $p$ value for $F$ tests with more than one degree of freedom.

$* p<.05$.

$* * p<.01$.

400-700 msec after word onset) with a right parietal maximum. This pattern is not visible in sentences about persons (see Figure 4, right panel). There appears to be a small negativity with a more anterior distribution than the classical N400 (most obvious at electrode F4 and C4).

Table 4 revealed that our pronoun manipulation in an omnibus ANOVA crossing factors antecedent type, pro-

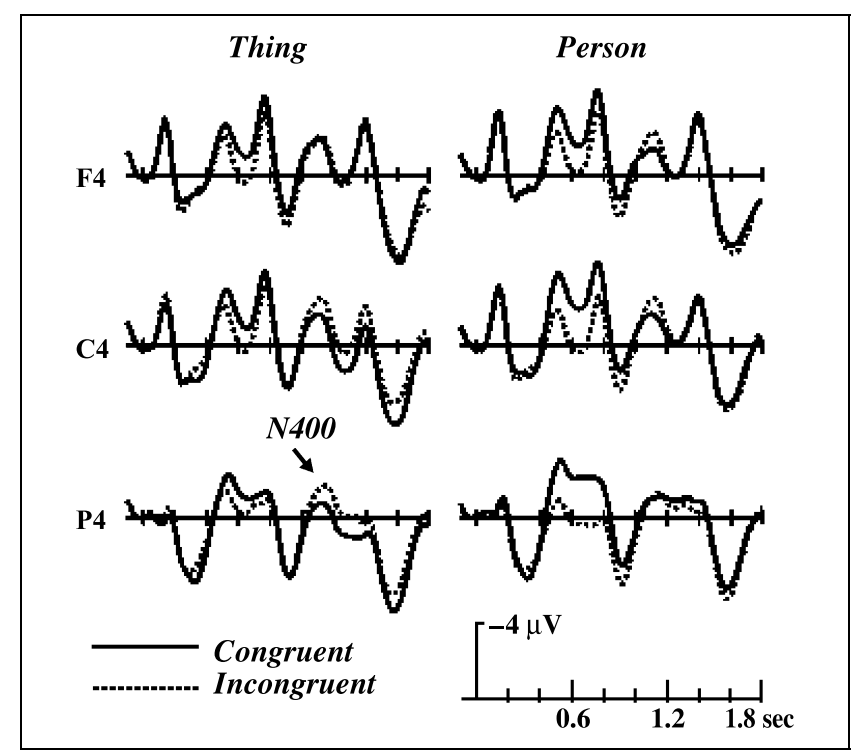

Figure 4. Grand average ERPs time-locked to the onset of the critical pronoun lasting until the end of the sentence with a thing as the antecedent (left panel) and with a person as antecedent (right panel) at a selected set of electrodes. The first word starts at $0 \mathrm{sec}$, the second word at $0.6 \mathrm{sec}$, and the sentence final word at $1.2 \mathrm{sec}$. The same scaling holds for Figure 5 . 
Table 4. Gender Agreement Effects: Mean ERP Amplitude ANOVAs in the 1000-1300 msec Latency Range after Onset of the Critical Pronoun (N400)

\begin{tabular}{lccc}
\hline Source & $d f$ & $F$ & $P(G G)$ \\
\hline Omnibus ANOVA (29 electrodes) & & & \\
Antecedent type (Person vs. Thing) & 1,15 & 1.75 & .2 \\
$\begin{array}{l}\text { Pronoun type (Congruent } \\
\quad \text { vs. Incongruent) }\end{array}$ & 1,15 & 0.95 & .3 \\
$\begin{array}{l}\text { Antecedent type } \times \text { Pronoun type } \\
\text { Antecedent type } \times \text { Electrodes }\end{array}$ & 1,15 & 3.58 & .08 \\
$\begin{array}{l}\text { Pronoun type } \times \text { Electrodes } \\
\text { Antecedent type } \times \text { Pronoun }\end{array}$ & 28,420 & 2.10 & .08 \\
$\quad$ type $\times$ Electrodes & 28,420 & 1.10 & .4 \\
& & &
\end{tabular}

Thing: Omnibus ANOVA (29 electrodes)

$\begin{array}{lccc}\text { Pronoun type }(\text { TC vs. TI) } & 1,15 & 6.36 & .02 * \\ \text { Pronoun type } \times \text { Electrodes } & 28,420 & 0.79 & .7\end{array}$

Thing: Parietal ANOVA (P3, Pz, P4)

$\begin{array}{llll}\text { Pronoun type }(\text { TC vs. TI) } & 1,15 & 12.86 & .003^{* *} \\ \text { Pronoun type } \times \text { Electrodes } & 2,30 & 0.09 & .9\end{array}$

Person: Omnibus ANOVA (29 electrodes)

$\begin{array}{lccc}\text { Pronoun type (PC vs. PI) } & 1,15 & 1.03 & .3 \\ \text { Pronoun type } \times \text { Electrodes } & 28,420 & 1.26 & .3\end{array}$

Person: Parietal ANOVA (P3, Pz, P4)

\begin{tabular}{llll} 
Pronoun type $(\mathrm{PC}$ vs. PI) & 1,15 & 0.31 & .6 \\
Pronoun type $\times$ Electrodes & 2,30 & 1.03 & .4 \\
Pronoun type $\times$ Electrodes & 2,30 & & \\
\hline
\end{tabular}

$\mathrm{PC}=$ congruent person; $\mathrm{PI}=$ incongruent person; $\mathrm{TC}=$ congruent thing; TI = incongruent thing; GG = Greenhouse-Geisser corrected $p$ value for $F$ tests with more than one degree of freedom.

$* p<.05$.

$* * p<.01$.

noun type, and electrodes did not show significant effects in the specified time window, but a trend. Separate analysis for thing-sentences showed a significant main effect for pronoun type in an omnibus ANOVA and in a parietal ANOVA, indicating an N400 (400$700 \mathrm{msec}$ ) effect. Analysis for person-sentences revealed no significant effects in this time window, indicating that the violation did not affect the processing of the word after the pronoun in this condition. An additional ANOVA on right fronto-central sites (C4, F4) did not reveal a significant main effect for congruency (Pc vs. Pi) for person-sentences, $F(1,15)=1.17, p<.3$.

\section{Discussion}

The aim of this experiment was to investigate the role of conceptual/semantic and syntactic information in the process of establishing co-reference between a pronoun and its antecedent. In German things have a clear syntactic gender. We therefore expected to tap into pure syntactic processing during the violation of the pronoun gender, which should be reflected by a P600. In contrast, persons as antecedent have an unambiguous biological gender, which coincides with syntactic gender. Thus, in the case of a person-antecedent, conceptual/semantic information (viz. the biological gender) and syntactic information might be used to establish co-reference. We found a more positive ERP for incongruent compared to congruent pronoun types. This P600 effect was larger for person-antecedent than for thing-antecedent type sentences. If we take only the overall P600 pattern into account, these findings suggest that establishing co-reference might be a syntactic process in general. Moreover, the fact that the P600 was larger for persons compared to thing-antecedents shows that the syntactic process, in this case the reanalysis of the sentence, might interact with semantics if semantic knowledge is available. Besides we found a small negativity at left parietal sites in the time window between 300 and $400 \mathrm{msec}$ after pronoun onset. This observed negativity, however, did not resemble a standard N400 effect, which usually is more prominent over the right hemisphere and lasts longer (Münte, Wierenga, et al., 2001; Kutas \& Hillyard, 1983; for a review, see Kutas \& van Petten, 1994). Therefore, we can only speculate here about a possible explanation. Because we found this effect within the thing-condition-where we expected pure syntactic gender information processing - this negativity could be due to a search for an actor outside the sentence in case of an incongruent pronoun, that is, leaving sentence level and search within the discourse model (from a cognitive point of view comparable to the anterior negative effect found by van Berkum, Brown, Hagoort, \& Zwitserlood, 2003 for discourse-referential ambiguity). Thus, it has to be considered that the preP600 negativity results could be interacting with the following P600. In other words, the P600 to thingpronouns might not really be smaller than that to person-pronouns, rather it might be the larger negativity to thing-pronouns that "pulls down" the subsequent P600 (i.e., this might be a component overlap issue rather than a pure P600 issue). We also observed an unexpected N400 at the word following the pronoun. This N400 was significant for thing-antecedent types, and was absent for person-antecedent types. As a possible interpretation, we suggest that this pattern reflects two types of processing: In the person case, the gender violation at pronoun position is so severe (syntactically and biologically bonding and resolution is signaling violation) that the reader/parser stops further attempts 
to integrate this mismatching pronoun immediately. Thus, no electrophysiological signs of integration attempts were found for the following word. In the thing case, the gender violation is purely syntactical and therefore the bonding process signals "violation," but due to the lack of any semantic information, a resolution does not take place at pronoun position. The reader/ parser is waiting for new incoming information to solve this incongruency. For example, the parser waits for (anticipates) a word that is related to any alternative antecedent in the discourse. But when the word matches the thing-antecedent in meaning (in our example: "gefüttert"), the comprehension system is unable to link the pronoun to any alternative antecedent. Therefore, the integration process of the incongruent pronoun finally signals violation at word position after the pronoun indexed by the N400. To test this assumption, we conducted a second experiment that manipulated the word following the pronoun and added discourse information.

\section{EXPERIMENT 2}

We performed this follow-up experiment for two reasons. First, we wanted to replicate the observed N400 pattern at the word following the pronoun for the thingantecedent sentence types. In addition, we wanted to test our assumption, that in the case of pure syntactic gender violation, as in German, in pronouns referring to things, the system keeps on looking for a meaning in the sentence or alternatively within the discourse. We used thing-antecedents and corresponding pronoun violations that were identical to those used in the first experiment. A context was created by adding a sentence preceding the target sentence. This sentence always introduced a person as an additional antecedent (i.e., a potential alternative to the thing-antecedent). This person could either have the same syntactic gender as the thing in the second sentence (ambiguous; A) or not. Therefore, the person was either congruent (C) or incongruent (I) to the pronoun. In addition, the word following the pronoun could either refer in meaning to the thing or to the alternative discourse person, leading to six experimental conditions in total (Table 5). In our example, the word "gefüttert" [lined] can only refer to the thing-antecedent "Jacke" (context: thing; CT) within the same sentence, whereas the word "friert" [freezes] can only refer to the person (context: person; CP)-to the alternative antecedent outside the sentence. The underlying rationale is the following. If the pronoun matches either the within- or outside-sentence antecedent (CTA and CPA), there is no violation between the word following the pronoun and antecedent, and the process of co-reference is finished at this word position (ERP baseline condition). In the case of a pronoun-thing antecedent violation (CTI), (i) the parser waits for new
Table 5. Example Materials for the Follow-up Experiment

\begin{tabular}{|c|c|}
\hline Condition & Sentence \\
\hline \multicolumn{2}{|c|}{ CT: Context Thing } \\
\hline \multirow[t]{2}{*}{ A. ambiguous } & $\begin{array}{l}\text { Die Frau } \\
\text { kalten Schnee. }\end{array}$ \\
\hline & $\begin{array}{l}\text { Die Jacke } \text { feminine ist warm, weil } \\
\text { sie }_{\text {FEMALE/feminine }} \text { gefüttert }_{\text {THING }} \text { ist. }\end{array}$ \\
\hline \multirow[t]{2}{*}{ C. congruent } & $\begin{array}{l}\text { Der Mann } \\
\text { kalten Schnee. }\end{array}$ \\
\hline & $\begin{array}{l}\text { Die Jacke } \text { feminine ist warm, weil } \\
\text { sie }_{\text {feminine }} \text { gefüttert }_{\mathrm{THING}} \text { ist. }\end{array}$ \\
\hline \multirow[t]{2}{*}{ I. incongruent } & Der Mann steht im kalten Schnee. \\
\hline & $\begin{array}{l}\text { Die Jacke }_{\text {feminine }} \text { ist warm, weil } \\
\text { er }_{\text {MALE/masculine }} \text { gefüttert }_{\text {THING }} \text { ist. }\end{array}$ \\
\hline \multicolumn{2}{|c|}{ CP: Context Person } \\
\hline \multirow[t]{2}{*}{ A. ambiguous } & $\begin{array}{l}\text { Die Frau } \\
\text { kalten Schnee. }\end{array}$ \\
\hline & $\begin{array}{l}\text { Die Jacke } \text { feminine } \text { ist warm, weil } \\
\text { sie }_{\text {FEMALE/feminine }} \text { friert }_{\text {PERSON }} \text { schnell. }\end{array}$ \\
\hline \multirow[t]{2}{*}{ C. congruent } & $\begin{array}{l}\text { Der Mann } \\
\text { kalten } / \text { masculine steht im } \\
\text { kchnee. }\end{array}$ \\
\hline & $\begin{array}{l}\text { Die Jacke } \text { feminine }_{\text {ist warm, weil }} \\
\text { er }_{\text {MALE/masculine }} \text { friert }_{\text {PERSON }} \text { schnell. }\end{array}$ \\
\hline \multirow[t]{2}{*}{ I. incongruent } & $\begin{array}{l}\text { Der Mann } \\
\text { kale/masculine steht im } \\
\text { kalten Schnee. }\end{array}$ \\
\hline & $\begin{array}{l}\text { Die Jacke } \text { feminine }_{\text {ist warm, weil }} \\
\text { sie }_{\text {feminine }} \text { friert }_{\text {PERSON }} \text { schnell. }\end{array}$ \\
\hline
\end{tabular}

Translation: The man/woman stands in the cold snow. The jacket is warm, because she/he is lined/freezes fast. FEMALE = biological gender female; MALE = biological gender male; masculine $=$ syntactic gender masculine; feminine $=$ syntactic gender feminine; THING $=$ word refers to the thing in meaning; PERSON $=$ word refers to the person in meaning.

input related to either the within-sentence or a controlled outside-sentence antecedent, (ii) the parser checks the match between the new word and pronoun and (iii) between new word and within-sentence antecedent. (iv) In case of a no-match, the parser looks for alternative antecedents, namely, somewhere outside the sentence (Experiment 1), or in the preceding sentence (Experiment 2). Thus, the baseline conditions are those cases where the pronoun can refer back either to the thing-antecedent or the additional person-antecedent. Also, when the word following the pronoun refers back to the discourse antecedent, all words can be processed on-line without any problems. In contrast, an N400 is expected in two cases: (a) if the pronoun does not match the thing-antecedent, and the following word does not match the discourse-antecedent (CTI), or (b) if the following word does match the thing-antecedent 


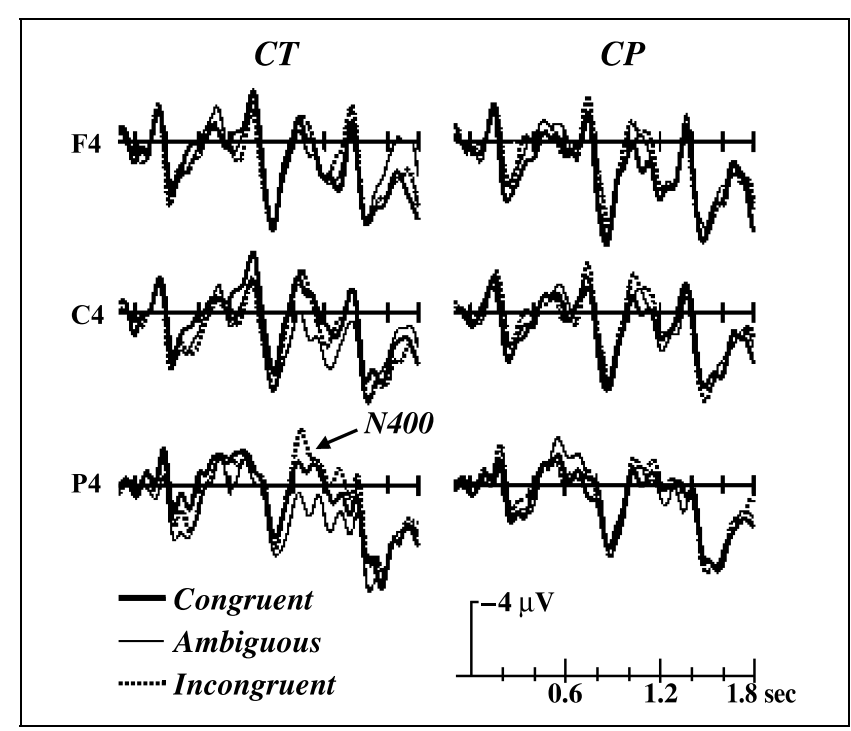

Figure 5. Grand average ERPs time-locked to the onset of the pronoun lasting until the end of the thing-context (CT) sentence (left panel) and the person-context (CP) sentence (right panel) at a selected set of electrodes.

and the pronoun, but does not match the discourseantecedent in meaning (CTC).

\section{Results}

The grand averages ERPs, time-locked to the pronoun up to the end of the sentence for the thing-context (left panel, CT) and for the person-context (right panel, CP), are shown in Figure 5. Around $1000 \mathrm{msec}$ after the pronoun (equivalent to $400 \mathrm{msec}$ after word following the pronoun), all conditions revealed a deflection towards negativity lasting to $1300 \mathrm{msec}$ with a right parietal maximum. In this 1000-1300 msec time window, this deflection was different within the thing-context for pronoun types with CTI being more negative than CTC and CTA. This suggested a modulation of the N400 component. This N400 pattern is not visible when the word following the pronoun refers in meaning to the person. However, there seems to be a trend towards a negativity with more anterior distribution for the person context.

The statistical analysis for the N400 time window (1000-1300 msec) for the word following the pronoun is reported in Table 6 . The omnibus repeated-measures ANOVA revealed no significant main effects. A more specific parietal analysis resulted in a significant main effect for pronoun types indicating indeed a manipulation of the N400. Separate planned comparison of pronoun types for the thing-context within the specified time window for electrode site P4 (the sites that showed most clearly the N400 in Experiment 1) revealed a significant difference between pronoun types. Additional planned pairwise comparison revealed significant differences between CTA and CTI $\left(t_{15}\right.$; one-tailed $=53.51, p<$
$.003)$ and between CTA and CTC $\left(t_{15}\right.$; one-tailed $=22.04$, $p<.04)$. In contrast, there was no difference between pronoun types for the person-context conditions. These results indicate that there was an N400 effect for pronoun types within the thing-context (see Figure 5, left panel), whereas this manipulation did not affect the word after the pronoun within the person-context (Figure 5, right panel). Because of a possible anterior

Table 6. Mean ERP Amplitude ANOVAs in the 1000-1300 msec Latency Range after Onset of the Pronoun (N400 at Following Word) for the Second Experiment

\begin{tabular}{lccc}
\hline Source & $d f$ & $F$ & $P(G G)$ \\
\hline Omnibus ANOVA (30 electrodes) & & & \\
Context (Person- vs. & 1,15 & 0.05 & .8 \\
$\quad$ Thing-antecedent) & & & \\
Pronoun (A vs. C vs. I) & 2,30 & 2.25 & .1 \\
Context $\times$ Pronoun & 2,30 & 0.56 & .6 \\
Context $\times$ Electrodes & 29,435 & 1.00 & .4 \\
Pronoun $\times$ Electrodes & 58,870 & 1.51 & .2 \\
Context $\times$ Pronoun $\times$ Electrodes & 58,870 & 0.94 & .5 \\
& & & \\
Parietal ANOVA $(P 3$, Pz, P4) & & & \\
Context (Person- vs. & 1,15 & 0.10 & .8 \\
$\quad$ Thing-antecedent) & & & \\
Pronoun (A vs. C vs. I) & 2,30 & 5.10 & $.01^{*}$ \\
Context $\times$ Pronoun & 2,30 & 0.20 & .8 \\
Context $\times$ Electrodes & 2,30 & 0.01 & .9 \\
Pronoun $\times$ Electrodes & 4,60 & 1.40 & .3 \\
Context $\times$ Pronoun $\times$ Electrodes & 4,60 & 2.23 & .09
\end{tabular}

Single electrode (P4)

Context (Person- vs.

$\begin{array}{lll}1,15 & 0.17 & .7\end{array}$

Thing-antecedent)

Pronoun (A vs. C vs. I)

$2,30 \quad 6.48 \quad .006 * *$

Context $\times$ Pronoun

$\begin{array}{lll}2,30 & 0.93 \quad .4\end{array}$

Planned Comparison P4: Thing-Context
Pronoun (A vs. C vs. I)
2,30
$4.13 .02 *$

Planned Comparison P4: Person-Context

Pronoun (A vs. C vs. I)

2,30

0.76

.8

$\mathrm{A}=$ ambiguous $\mathrm{C}=$ congruent $\mathrm{I}=$ incongruent; $\mathrm{GG}=$ GreenhouseGeisser corrected $p$ value for $F$ tests with more than one degree of freedom.

$* p<.05$

$* * p<.01$ 
negativity for the person-context, we performed an additional separate frontal ANOVA, the person-context which crossed the factors pronoun type (3; ambiguous vs. congruent vs. incongruent) and "electrode sites" (2 levels, C4, F4). This analysis resulted in no main effect for the person-context, $F(2,30)=0.55, p<.6$.

\section{Discussion}

The aim of the second experiment was to replicate the observed N400 at the word following the pronoun that has a syntactic gender violation with the within-sentence thing-antecedent. In addition, to test our post hoc explanation for the effect, we systematically added outof-sentence context and manipulated the word following the pronoun. As a replication of Experiment 1, we observed a more negative effect on the word following the pronoun within an incongruent sentence about things, but no effects for pronouns referring to a person out of the sentence. For the thing-context, the incongruent condition was more negative than the congruent condition (see Figure 5). This effect could be interpreted as an ongoing integration process in order to get the meaning of the pronoun right. This revision might be characterized by a searching process for an alternative antecedent in the discourse. Therefore, the parser waits for new information to solve this incongruity (i.e., expecting a relation to an alternative antecedent in the discourse). The $\mathrm{N} 400$ occurs if this process fails. It fails (a) if the pronoun does not match the thingantecedent, and the following word does not match the discourse-antecedent in meaning (CTI), or (b) if the following word does match in meaning with the thing-antecedent and the pronoun, but does not match with the discourse-antecedent in meaning (CTC). In contrast, in the person-case a revision does not take place at the word following the pronoun, indicating that the integration process for these pronouns seems to be finished right after pronoun processing due to a reliable declining of bonding/resolution of pronoun and person-antecedent.

\section{GENERAL DISCUSSION}

We conducted two experiments to investigate the role of syntactic and semantic information in the establishment of pronoun resolution in sentence reading. In Experiment 1, congruency was manipulated in sentences with either persons or things as antecedents. For incongruent sentences with person as well as thing-antecedents, we found a clear P600 effect at pronoun position, indicating an involvement of syntactic information and/or sentence reanalysis during pronoun processing. This $\mathrm{P} 600$ finding is in line with other ERP findings (Schmitt et al., 2002; Osterhout, Bersick, et al., 1997; Osterhout \& Mobley, 1995).
The P600 was significantly more strongly in sentences with a person than a thing as an antecedent. Granted the assumption that the size of the P600 effect reflects the effort of reanalyzing and/or syntactically repairing the sentence at pronoun position, this result indicates a larger effort to reanalyze and/or repair in sentences with persons (in which both types of gender are violated) compared to things (violation of syntactic information only). The observed difference in P600 effects might not just be an indicator for syntactic violations. Rather, it might be a response to reanalysis of the sentence as well, including both syntactic and semantic aspects (for a discussion, see Münte, Heinze, et al., 1998). Granted the assumption that the difference in size is related to a component-overlap of the pre-P600 negativity (i.e., which "pulls down" the P600 to thingpronouns) as indicated in Discussion 1, this result could indicate that already at pronoun position the comprehension system is prepared to search for a possible animate discourse-antecedent (i.e., another person). This possibility is confirmed by the unexpected finding in Experiment 1. We found an N400 effect in incongruent sentences about things at the word following the pronoun, indicating ongoing semantic integration/reanalysis. This N400, however, was only observed for sentences with a thing as within-sentence antecedent, and not when this was a person.

In Experiment 2, we replicated and investigated this finding further. We provided an additional discourse sentence with either a female or a male person as subject as an alternative antecedent preceding the thingsentences of the first experiment. Furthermore we manipulated the word after the pronoun in such a way that it either belonged to the thing-antecedent (thingcontext) or to the new person-antecedent (personcontext) in the preceding discourse sentence. Thus, the pronoun in the thing-sentence could either refer back ambiguously to the thing-antecedent or to the person-antecedent or congruently/incongruently to the thing-antecedent or finally congruently/incongruently to the person-antecedent. Our ERP data revealed a clear N400 effect on the word following the pronoun for the thing-context whenever there was a violation, but not in the person-context. The N400 has been shown to be sensitive to semantic integration (Kutas \& van Petten, 1994). Thus, our N400 effect indicates that there was still an ongoing integration process on the word following the pronoun if it referred to the thing in meaning, but not if it referred to the person. Furthermore, on the basis of the observed N400 effect size, this integration can be differentiated depending on the given context. For example, the N400 was of medium size when the pronoun and the following word agreed with the withinsentence antecedent, but when the following word did not fit in meaning to the discourse-antecedent. Based on the type of violation in this condition, we suggest that this medium-sized N400 does not reflect an integration 
problem within the sentence, but rather a violation of discourse processing. The $\mathrm{N} 400$ was large when the pronoun did not agree in gender with the within-sentence antecedent and the following word did not agree in meaning with the discourse-antecedent. The larger N400 indicates a sort of double violation (i.e., a failure of agreement within the sentence, and within the discourse). So far, we cannot say which of the agreement processes comes first or has priority. It seems as if both-the within- and between-sentence integrations-take place as default. So, in case of no agreement, the parser anticipates for a disjoint co-referential relation preferably to a person-antecedent because of the preference for pronouns to refer to persons. In order to anticipate incongruent thing-sentences, the language system expects a word with such a semantic content that the pronoun fits referring to the discourseperson. "Gefüttert" is not such a word and therefore there is a lexical integration problem of this word. For the person-context, there is no $\mathrm{N} 400$ for the word following the pronoun. In this case, the comprehension system is not hampered in searching for an alternative antecedent after the pronoun because this word refers in meaning to the person-antecedent and a disjoint coreferential relation is established.

Taken together, data of the two experiments show that at pronoun position violations in syntactic and in a combination of syntactic and biological gender violation are reflected in the P600. The larger P600 for person compared to thing antecedent types shows that the $\mathrm{P} 600$ is sensitive to the underlying semantic information of the antecedent (here, whether or not it has biological gender). The observed $\mathrm{N} 400$ on the word following the pronoun in case of thing but not person antecedent types within the same sentence indicates, for the first time, that after violations of the pronoun, the parser tries to integrate at later sentence positions, and it does so differently for each type of antecedent.

\section{METHODS}

\section{Experiment 1}

Subjects

Twenty-one subjects volunteered for paid participation in the experiment. Five datasets could not be used due to too many artifacts or technical problems. The final population of subjects comprised 16 native speakers of German, age range 20 to 30 , mean age 24.6 years, 8 women. All subjects had normal or corrected-to-normal vision, were right-handed according to self-report, and were neurologically healthy.

\section{Material}

Two-hundred forty sentences, 120 about persons and 120 about things, were constructed. Each sentence had two clauses. The first clause in each sentence was the main clause, which described a state of a person or a thing. The person or the thing was the subject of the main clause, and formed the antecedent of the pronoun following later. Care was taken to guarantee equal word frequencies for persons and things using the CELEX database (Burnage, 1990). The second clause was a subordinate clause introduced by the conjunction weil (because). This conjunction was followed by the critical word, a pronoun referring to the person or the thing. All sentences were then copied and the congruent pronoun was replaced by an incongruent pronoun (see Table 1 for examples). This resulted in a total of 480 sentences and in four conditions with 120 sentences per condition: (PC) A person as an antecedent with a congruent pronoun, (PI) a person with an incongruent pronoun, and (TC) a thing as an antecedent with a congruent pronoun, (TI) a thing with an incongruent pronoun. The sentences were pseudorandomized over four blocks, such that each condition appeared 30 times in each block, and that the sentences with the same subjects in the main clause were not in the same block.

In order to keep participants attentive, and to guarantee that they read the sentences, every $10 \pm 5$ sentences one of 48 comprehension questions was presented. These questions pertained to the immediately preceding set of $10 \pm 5$ sentences and required a yes/no response. Subjects had to press one out of two buttons for "yes" or "no." This task was independent of the pronoun manipulation.

The words were presented visually on a back projection screen at a distance of $100 \mathrm{~cm}$. Critical words subtended $0.5^{\circ}$ of visual angle in height and $1.2^{\circ}$ in width.

\section{Procedure}

Participants were tested in a dimly lit sound-attenuating room. They were seated in a comfortable chair. Their instructions were to read the sentences carefully, and to answer the questions related to the sentences from time to time. They were free to blink between the sentences and while answering the questions, but were instructed to fixate on the screen, to be as relaxed as possible, and to avoid all movement while reading the sentences.

A trial started with a fixation cross in the middle of the screen, presented for $2050 \mathrm{msec}$ with a 300-msec interstimulus interval, and was followed by the word-by-word presentation of the sentence. Each word was presented for $350 \mathrm{msec}$ with a 250-msec interstimulus interval. Sentence ending words were presented with a dot indicating the end of a sentence, followed by a blank screen for $850 \mathrm{msec}$.

Questions were presented on the screen for 4 sec. One block lasted approximately 15 minutes. The entire 
experiment, including instructions, electrode application, and removal took about 2.5 hours.

\section{EEG Recording and Analysis}

Electroencephalography (EEG) signals were registered with a digitization rate of $254 \mathrm{~Hz}$ and filtered with a band pass of DC to $50 \mathrm{~Hz}$. Twenty-nine tin electrodes were applied according to the 10/20 system (positions: $\mathrm{Fz}, \mathrm{Cz}$, Pz, Oz, Iz, Fp1/2, F3/4, F7/8, T7/8, C3/4, P3/4, O9/10, P7/ P8, Fc1/2, Cp1/2, Po3/4, Po7/8). Bio-signals were recorded with a left mastoid reference, and were off-line re-referenced to the mean of the activity at the two mastoids. Horizontal eye movements were recorded from an electrode behind the right lateral orbital ridge and referenced to an electrode at the left orbital ridge. Eye blinks and vertical movements were recorded from an electrode below the right orbital limb and referenced to the left mastoid. EEG and EOG signals were amplified using a 32-channel Synamps amplifier. All electrode impedances (EEG and EOG) were kept below $5 \mathrm{k} \Omega$.

From the continuous signal epochs were created of $1006 \mathrm{msec}$ starting $100 \mathrm{msec}$ prior to pronoun onset. These epochs were monitored for artifacts, such as eye movements, by an automated procedure. Trials including artifacts were rejected from further analysis. By averaging the remaining artifact-free epochs per condition, the ERPs were derived. The mean number of trials contributing to the average was 107 (PC and TC conditions) and 108 (PI and TI conditions). Waveforms were quantified by mean amplitude measures to assess N400 (time window 300 to $400 \mathrm{msec}$ ) and P600 (400 to $700 \mathrm{msec}$ ) components. Note that the N400 time window diverges from the standard N400 time window (usually between 300 and $500 \mathrm{msec}$ ) in order to avoid overlap with the P600 time window. These windows were derived from previous pronoun experiments of our group (Schmitt et al., 2002) and corroborated by visual inspection of the grand average ERPs. These measures were subjected to repeated-measures ANOVA that crossed the factors antecedent type (2; person vs. thing), pronoun type (2; congruent vs. incongruent), and "electrode sites" (29 levels). The GreenhouseGeisser correction for inhomogeneity of covariance was applied whenever an evaluated effect had more than one degree of freedom in the numerator. Reported $p$ values are corrected. Additionally, we compared the mean amplitudes of conditions in the $\mathrm{N} 400$ time window by separate analyses for pronoun type (PC vs. PI, and TC vs. TI). Finally, ERPs were averaged for $2012 \mathrm{msec}$ epochs with a 100-msec prestimulus interval in order to analyze the processing of the end of the sentence. These measures were subjected to repeated ANOVA following the same logic as above and an additional analysis for the parietal line ( $\mathrm{P} 3, \mathrm{Pz}, \mathrm{P} 4)$ in a time window from 1000 to $1300 \mathrm{msec}$ (corresponding to a $400-700 \mathrm{msec}$ time window for the word after the pronoun).

\section{Experiment 2}

The second experiment followed the same procedure as the former experiment with regard to the timing of stimulus display, and EEG recording (despite one additional electrode-Fpz).

\section{Subjects}

Twenty subjects volunteered for paid participation in the second experiment. Four datasets were rejected due to too many artifacts. The final population of subjects consisted of 16 native German speaker, age range 20 to 27 , mean age 22.0 years, 11 women. All subjects had normal or corrected-to-normal vision, were righthanded according to self-report, and were neurologically healthy.

\section{Material}

Fifty congruent thing-sentences of the former experiment were selected. Additionally, we created two types of discourse sentences with a person as a subject who had either the same gender as the thing (ambiguous pronoun resolution, CTA and CPA) or not (see Table 5 for example material). If context person and thingantecedent had different gender, the pronoun "he" could refer back to the man and the pronoun "she" to the jacket in our example. Furthermore, we replaced the word following the pronoun ("gefüttert" lined) with a word ("friert" freezes) that resolves the sentence in such a way that the second clause belongs to the person in the added context-sentence. At that point of sentence processing, the re-reference of the pronoun is clear: either being congruent (CTC) or incongruent (CTI) to the thing ("Jacke and gefüttert" jacket and lined) or either congruent (CPC) or incongruent CPI) to the person ("Mann/Frau and friert" man/woman and freezes). Thus, the material resulted finally in six different conditions. The material was distributed across two lists remaining 25 sentences per condition in one list, counterbalancing the thing-antecedent and the word following the pronoun. On a given list each thing-antecedent appeared three times with one person-context and two thing-context words following the pronoun or vice versa. Sentences on a list were pseudorandomized over two blocks in such a way that the same thingantecedents were kept apart as far as possible. We measured eight subjects per list. They were pooled again for later analyses.

\section{Analyses}

The time window for the mean amplitude analyses of the N400 was 1000-1300 msec after pronoun onset, as in Experiment 1 . The mean amplitude values were sub- 
jected to repeated-measures ANOVA that crossed the factors context (2; person-reference vs. thing-reference), pronoun type (3; ambiguous vs. congruent vs. incongruent), and "electrode sites" (30 levels). Additionally, we compared the mean amplitudes of conditions in the N400 time window by separate analysis for the parietal line $(\mathrm{P} 3, \mathrm{Pz}, \mathrm{P} 4)$, and by means of planned comparisons between conditions for the single electrode P4. P4 was singled out because of the observed maximum of the effect in Experiment 1, and because of the expectation of a right centro-parietal hemispheric maximum for the N400 amplitude. Reported $p$ values are corrected via Greenhouse-Geisser correction for inhomogeneity of covariance.

\section{Acknowledgments}

The research reported in this article was supported by a grant of the Dutch Science Foundation (NWO) to BMJ (she also published under her maiden name Schmitt), and by a grant MU1311/9-1 of the German Science Foundation (DFG) to TFM, as a bilateral cooperation project DFG/NWO. We thank Michael Scholz for technical support and Daniel Wiswede for collecting the ERP data of the follow-up experiment.

Reprint requests should be sent to Bernadette Jansma, Maastricht University, Faculty of Psychology, Department of Neurocognition, P.O. Box 616, 6200 MD Maastricht, The Netherlands, or via e-mail: B.Jansma@psychology.unimaas.nl.

\section{Note}

1. In case of modularity, this complex has to be identical to the sum of the separate components (as shown by Osterhout \& Nicol, 1999). A complex could also show an interaction (in case the sum is not identical to both component effects in isolation).

\section{REFERENCES}

Burnage, G. (1990). CELEX: A guide for users. Nijmegen, The Netherlands: Centre for Lexical Information, University of Nijmegen.

Carreiras, M., Garnham, A., Oakhill, J., \& Cain, K. (1996). The use of stereotypical gender information in constructing a mental model: Evidence from English and Spanish. Quarterly Journal of Experimental Psychology, Section A: Human Experimental Psychology, 34, 41-62.

Friederici, A. D., \& Mecklinger, A. (1996). Syntactic parsing as revealed by brain responses: First pass and second pass parsing process. Journal of Psycholinguistic Research, 25, 157-176.

Garnham, A., Oakhill, F., Ehrlich, M. F., \& Carreiras, M. (1995). Representations and processes in the interpretation of pronouns: New evidence from Spanish and French. Journal of Memory \& Language, 34, 41-62.

Garrod, S. C., \& Sanford, A. J. (1994). Resolving sentences in a discourse context. In M. A. Gernsbacher (Ed.), Handbook of Psycholinguistics (pp. 675-698). New York: Academic Press.
Garrod, S. C., \& Terras, M. (2000). The contribution of lexical and situational knowledge to resolving discourse roles: Bonding and resolution. Journal of Memory \& Language, 42, 526-544.

Gernsbacher, M. A. (1991). Comprehending conceptual anaphors. Language and Cognitive Processes, 6, 81-105.

Gordon, P. C., \& Hendrick, R. (1998). The representation and processing of coreference in discourse. Cognitive Science, 22, 389-424.

Hagoort, P., Brown, C. M., \& Groothusen, J. (1993). The syntactic positive shift (SPS) as an ERP measure of syntactic processing. Language and Cognitive Processes, 8, 439-483.

Hagoort, P., Brown, C. M., \& Osterhout, L. (1999). The neurocognition of syntactic processing. In C. Brown \& P. Hagoort (Eds.), The neurocognition of language (pp. 273-316). Oxford: University Press.

Hankamer, J., \& Sag, I. A. (1976). Deep and surface anaphora. Linguistic Inquiry, 7, 391-428.

King, J. W., \& Kutas, M. (1997). Is she an engineer? Brain potentials and anaphora. Poster presented at the Fourth Annual Meeting of the Cognitive Neuroscience Society, Boston.

Kutas, M., Federmeier, K. D., Coulson, S., King, J. W., \& Münte, T. F. (2000). Language. In J. T. Cacioppo, G. Tassinary, \& G. G. Berntson (Eds.), Handbook of psychophysiology (2nd ed., pp. 576-601). New York: Cambridge University Press.

Kutas, M., \& Hillyard, S. A. (1980). Reading between the lines: Event-related brain potentials during natural sentence processing. Brain \& Language, 11, 354-373.

Kutas, M., \& Hillyard, S. A. (1983). Event-related brain potentials to grammatical errors and semantic anomalies. Memory \& Cognition, 11, 539-550.

Kutas, M., \& van Petten, C. K. (1994). Psycholinguistics electrified: Event-related brain potential investigations. In M. A. Gernsbacher (Ed.), Handbook of psycholinguistics (pp. 83-143). San Diego: Academic Press.

Münte, T. F., Heinze, H. J., Matzke, M., Wieringa, B. M., \& Johannes, S. (1998). Brain potentials and syntactic violations revisited: No evidence for specificity of the syntactic positive shift. Neuropsychologia, 36, 217-226.

Münte, T. F., Wierenga, B. M., Weyerts, H., Szentuki, A., Matzke, M., \& Johannes, S. (2001). Differences in brain potentials to open and closed class words: Class and frequency effects. Neuropsychologia, 39, 91-102.

Osterhout, L., Bersick, M., \& McLaughlin, J. (1997). Brain potentials reflect violations of gender stereotypes. Memory \& Cognition, 25, 273-285.

Osterhout, L., \& Holcomb, P. J. (1992). Event-related brain potentials elicited by syntactic anomaly. Journal of Memory E Language, 34, 785-806.

Osterhout, L., \& Mobley, L. A. (1995). Event-related brain potentials elicited by failure to agree. Journal of Memory E Language, 34, 739-773.

Osterhout, L., \& Nicol, J. (1999). On the distinctiveness, independence, and time course of the brain responses to syntactic and semantic anomalies. Language and Cognitive Processes, 14, 283-317.

Rugg, M. D., \& Coles, M. G. H. (1995). The ERP and cognitive psychology: Conceptual issues. In M. D. Rugg \& M. G. H. Coles (Eds.), Electrophysiology of mind: Event-related brain potentials and cognition (pp. 27-39). New York: Oxford University Press.

Schmitt, B. M., Lamers, M., \& Münte, T. F. (2002). Electrophysiological estimates of biological and syntactic gender violation during pronoun processing. Cognitive Brain Research, 14, 333-346. 
St. George, M., Kutas, M., Martinez, A., \& Sereno, M. I. (1999). Semantic integration in reading: Engagement of the right hemisphere during discourse processing. Brain, 122, 1317-1325.

Swaab, T. Y., Camblin, C. C., \& Gordon, P. C. (2004). Electrophysiological evidence for reversed lexical repetition effects in language processing. Journal of Cognitive Neuroscience, 16, 1-12. van Berkum, J. J., Brown, C. M., Hagoort, P., \& Zwitserlood, P. (2003). Event-related brain potentials reflect discourse-referential ambiguity in spoken language comprehension. Psychophysiology, 40, 235-248.

van Berkum, J. J., Hagoort, P., \& Brown, C. M. (1999). Semantic integration in sentences and discourse: Evidence from the N400. Journal of Cognitive Neuroscience, 11, 657-671. 